\title{
Large-scale Manufacturing Enterprises in Technological Innovation Team Building
}

\author{
Bin ZHENG ${ }^{1, a}$ Chengbo $\mathrm{HU}^{2, \mathrm{~b}}$ \\ ${ }^{1}$ Wuhan University of Technology, China \\ ${ }^{2}$ Shenyang Aerospace University, China \\ aemail:853106030@qq.com; bemail:huchengbo79@yahoo.com.cn
}

Keywords: manufacturing enterprises; technological innovation; team; building.

\begin{abstract}
Large-scale manufacturing enterprises in technological innovation team is the main new technologies and new products, technological innovation activities, production process innovation activities and product development activities of enterprises are inseparable from the role of large-scale manufacturing enterprise technical innovation team. Large manufacturing enterprises in technological innovation team effective use of resources, and promote the update and improvement of the entire organization. Through the efforts of large manufacturing enterprises in technological innovation team can make the enterprises have grown rapidly and continue to grow, in a dominant position in the market. The construction and management of the team of technology innovation is the core, strengthen team construction and management of large-scale manufacturing enterprises' technological innovation is also a method of problem-solving.
\end{abstract}

\section{Introduction}

Large-scale manufacturing enterprises in technological innovation team is the main new technologies and new products, technological innovation activities, production process innovation activities and product development activities of enterprises are inseparable from the role of large-scale manufacturing enterprise technical innovation team. Sound technical innovation team to enable businesses to benefit in many ways, the best players together and technological innovation team can use a variety of resources. Enterprises have grown rapidly and growing through the efforts of technical innovation team, in a dominant position in the market. However, if you want to achieve these objectives and requirements, technological innovation team needs to have the elements of a variety of different skills, qualities, experience, tools and innovative ideas. In these elements, the management is the core technology innovation team, as long as this technological innovation team to be given full play.

\section{Large-scale Manufacturing Enterprises in the Form of Technical Innovation Team}

An effective technical innovation teams closely coordinate with various departments of the enterprise. Large-scale high-tech manufacturing enterprises in technological innovation team should be a variety of special abilities organic combination, but the various capabilities together will produce complex innovation activities, and sometimes it is quite difficult. Have a variety of criteria, in theory and in practice, to define the type of large manufacturing enterprises in technological innovation team, the most important are two basic methods: First, based on the performance in the form of enterprise technology innovation organization, the external manifestation research emphasis on technological innovation activities; The second is based on the organization's internal structure of technological innovation research division, focused on technology innovation and the internal mechanism of the innovation performance.

Ranks of the Organization in the Form of Large-scale Manufacturing Enterprises' Technological Innovation. According to the manifestation of the innovation activities, according to the Chinese Fu Jiaji scholars with Yunhuan, Gao Jian, the organizational form of the technology innovation team: Within enterprises and within the entrepreneurs, innovative team, new business development, enterprise technical centers and enterprise dynamic alliance. 
Structure in the Form of Large Manufacturing Enterprises in Technological Innovation Team. According to the organization's internal structure of technological innovation and its innovative structure, draw domestic and foreign research in this regard, Drucker, Fuji-moto and Steven the first text on the product development organization research technology innovation team is divided into functions of the system, staff functions of the system, to participate in the system and the autonomy four types.

The Choice of the Form of Large Manufacturing Enterprises in Technological Innovation Team. Select an appropriate type of team should be based on the specific circumstances of the business or organization. In general, to adhere to the basic principles of innovative team structure is not only compatible with the capabilities and resources of the organization, but also to match with the type of innovation projects. Is generally believed that the higher technical and project the best functions of the system; Projects like the new basic technology or the concept of a new generation of products need excellent solution requires do in participation system; General Staff teams capable of handling derived or strengthen innovation projects, and enable them to live a valuable training; Drastic changes or breakthroughs project is best done by autonomous teams.

\section{Large Manufacturing Enterprises in Technology Innovation Team Composition}

Operation mechanism and organizational structure of the internal structure of a variety of technical innovation team is different, but the basic constituents are similar, that is, in order to ensure the smooth progress of the innovation activities, it must have the necessary innovation activities participants undertake technical innovation team different tasks, play different roles. Which plays a key role in some of the roles each type of technology innovation teams have.

Project managers. Project managers is to plan, organize and control the work of the leading innovation projects in order to achieve the goal of innovation. Or, the completion of the project managers leading innovation team innovation project objectives. He should have experience in the development of innovative ideas, good at listening to the views of the members of the innovation team, helpfulness, without partiality, and senior managers is an understanding of the innovation team members. His basic function is to coordinate the activities of the members of the innovation team, so that they become a harmonious whole, dutifully fulfill their respective work.

The Innovative Idea of the Producers. Innovative ideas generated by scientists or engineers' creative, innovative spirit, the received the good education, like the address cutting-edge issues. Technological innovation activities, creativity is the foundation, there is no creativity into full play, it is impossible to obtain the success the technological innovation. Innovation activities need innovative ideas generated by, they will not be able the produce innovative ideas, the course the not to mention the success the innovative activities. Based the psychology research, creativity, mainly including the exploration of the sensitivity the problem, unifying thinking activities ability, the ability the transfer experience and lateral thinking ability, Lenovo ability, memory, flexibility the thinking, the ability to evaluate, generate ideas ability to foresee the ability.

Technical Experts. The technology innovation activities encountered and found many technical problems, which is inseparable from technical experts to solve the problem. Technical experts timely identify problems and to solve the problem is essential, the ability to effectively solve the problem will affect the success or failure the technology innovation activities. Technical experts to encourage innovation team members to identify problems early and help solve the problem. Timely detection of problems, there the plenty of time can be used to design a mature solution, so the cost solve problem well the to minimize damage to other parts. Problem-solving, technical experts play a key role, he is responsible the propose the solution the problem, and leading members the technology innovation team the solve the problem.

Information Gatekeepers. The information gatekeepers generally by scientists and engineers to serve as or act as the marketing staff to have a technical background, focus the relevant market information and effective communication with companions engaged the technical work. Information gatekeepers innovative organizations internal and external information linked bonds, according to supplement innovation resources to strengthen the innovation team adjustment 
innovation goals. Innovation activities need all the market information and technical information, the not timely, accurate, comprehensive information, innovation activities are unlikely to succeed, which requires innovation team has the critical role the information gatekeepers.

Innovation Advocates. Innovation advocates, supporters and advocates of innovation projects or innovation activities, with a strong spirit of innovation, and the wide range of interests, a wide range of activities, actively promote innovation, good publicity and acceptance of innovative ideas to others. Innovation advocate is usually a more experienced, older project managers or entrepreneurs, he can guide and help innovative organizations in the other members on their behalf with the senior leadership dialogue, inspire innovation organization members to work actively to make innovative programs to methodically move forward.

\section{Strengthen Large Manufacturing Enterprise Technology Innovation Team Management}

Strengthen the Planning, Organization and Control of the Technological Innovation Activities. In order to make innovation activities carried out smoothly, and ensure the quality of technological innovation projects done on time, we must strengthen technological innovation team building innovation projects planned, organized and controlled. To control innovation activities also need to design an innovative project management information system to track the actual process of innovation, process and plan for comparison, as well as when the effective control of the innovation activities.

Scientific and Rational Technological Innovation Team Authorized. Project managers to fully understand the significance of the authorization, and seriously and properly authorized to innovation team pressure and power, to ensure that the innovation team to work effectively. Innovation and team members to achieve the expected innovations within the scope of their duties, according to the scope of work plan, and work with the resources to control the final completion of the objectives and tasks necessary authorization is indispensable.

To Strengthen the Management of Technological Innovation Team Growing Up. The innovation team is a groups work together to achieve innovation goals, innovation activities is innovative team members work together to achieve innovation goals. In order to successfully achieve the goals of innovation, the personnel involved in the innovation must be composed of dynamic, creative and innovative team efficiency, must strengthen the management of the process of growth of the innovation team. Innovation activities, the project manager should let the members of the innovation team to give full play to their initiative, but also necessary to provide guidance and advice to members, in order to ensure the vitality and direction of innovation teams. Project managers ensure the validity of the authorization led to the establishment of innovative project management information and control systems, control innovation activities in a timely manner.

Improve the Efficiency of the Technology Innovation Team. All aspects of technological innovation team needs innovation activities closely together, the key roles and associated personnel in close collaboration with the rational allocation of resources for innovation. Specifically, an effective technological innovation team to meet the following conditions: innovation targeted, realistic; reasonable allocation of resources for innovation; a high degree of trust and close cooperation between the innovation team members. The basic method to improve the efficiency of innovation teams each innovation team is to improve the efficiency and increase the cohesion of the innovation team. One is to increase the efficiency of the innovation team for innovative players to establish the confidence and trust of the heart, there are high expectations for themselves and others; actively involved in communication and encourage each team member and strive to build an environment for innovation activities. The other hand, increased innovation and team cohesion, and project managers to respect and care for all innovation players, and view them as the wealth of the innovation team. Innovative players as part of the innovation team to cooperate with each other, to communicate, share information and knowledge, and work for a common goal. Timely and appropriate recognition and reward innovation team and contribute to the innovation team. Strengthen ideological education and spiritual encouragement, so that all the players are loyal to the innovative team of innovation and innovative career. 


\section{Conclusion}

Through the efforts of large manufacturing enterprises in technological innovation team can make the enterprises have grown rapidly and continue to grow, in a dominant position in the market. However, the requirements of modern large-scale manufacturing enterprises in technology innovation team has a variety of different skills, qualities, experience, tools and innovative ideas to achieve these goals. Of these, at its core is the role of the modern technological innovation team will be able to be given full play. In many cases, it is often due to the mismanagement of the modern large-scale manufacturing enterprises in technology innovation team and lead the enterprise can not achieve the desired success. Visible, the core of the problem is the construction and management of technical innovation team, and strengthen team building and management of large-scale manufacturing enterprises' technological innovation is to solve the problem.

\section{References}

[1] Chengbo Hu, On the technological innovation of China's aviation manufacturing enterprises[J], Business Research,2010.8

[2] Yulin Zhao, Economics of Innovation[M], China Economic Press,2006

[3] Gong Cheng, Enterprise Technology Innovation Theory[M], Shanghai University of Finance and Economics Press,2005.1

[4] Jiaji Fu, Technology Innovation[M], Tsinghua University Press,1998

[5] Chengbo Hu,On the type of enterprise technological innovation Strategy and strategic choice[J], AIMSEC2011,2011.8 